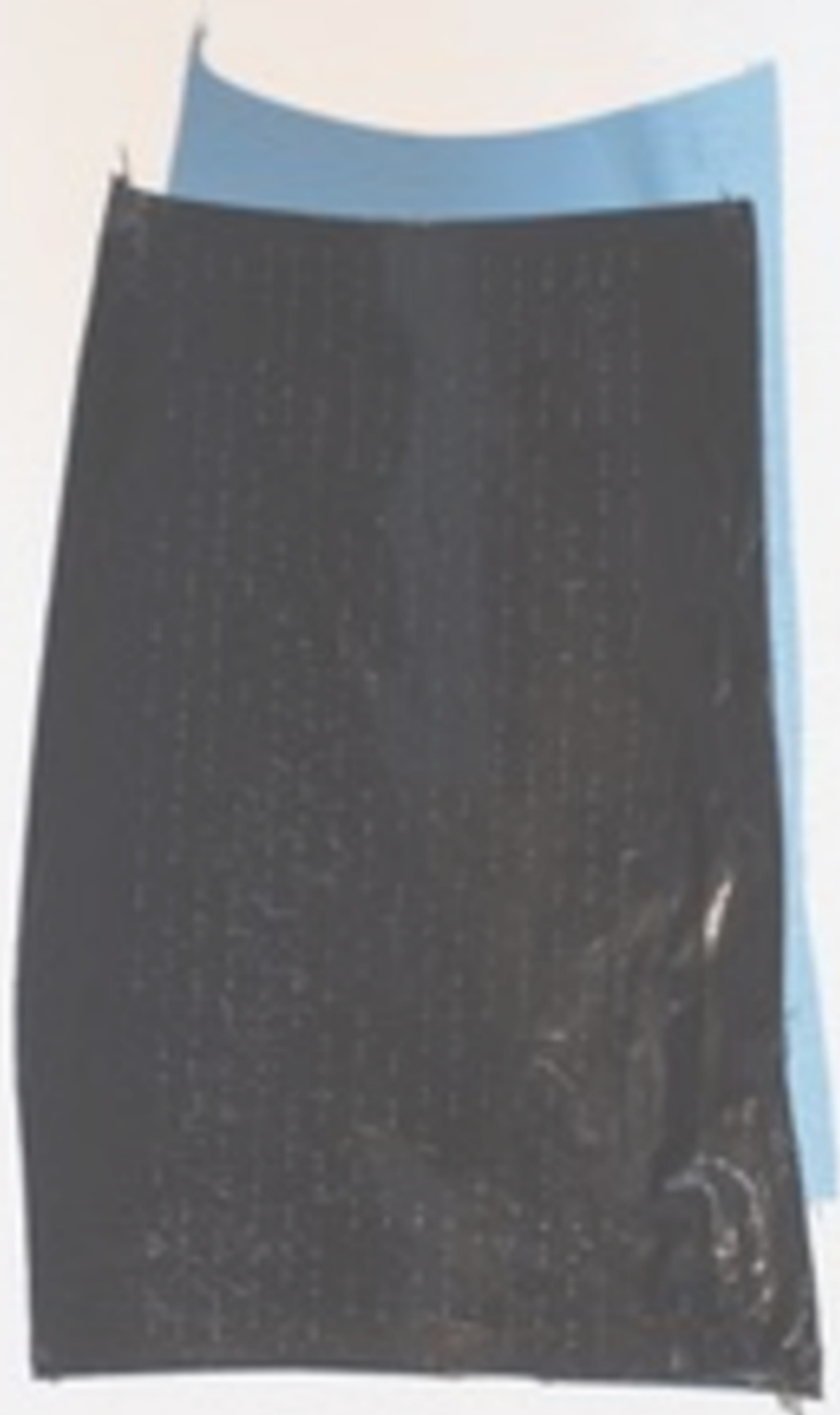

Artwork by Michael René Sell; essay by Isabel Elisabeth Winter. 


\title{
Rethinking Social Norms Through Performance Art
}

\author{
Isabel Elisabeth Winter
}

Welcome to post-materialism. This term is used in sociology to describe a new shift of values. It is assumed that higher values slowly replace those traditional and material, thus slowly introducing social change. By material values, we mean, among other things, a pursuit of material prosperity, a strong need for security and the maintenance of order. On the contrary, post-materialism focuses on values like individualism, autonomy, selfrealization, freedom, culture and art. In the contemporary era, we find ourselves in such a time of transition. With the Inglehart Index, named after the originator of the theory developed in the 1970s, Ronald Inglehart, the transformation can even be detected statistically. If we believe in this survey and evaluation, a rapid increase in post-material values can be seen in German-speaking countries since the 1980s. This tendency only seems to have accelerated; evidence for this includes present day public discourses about feminism, the fight for queer rights and the spread of individualism into every facet of a normal daily life. Also, art is more prominent than ever before in society, which can be seen in abnormal auction prices for art pieces.

It is said that art is the mirror of society, along with its potential to protest and become a statement for socially relevant topics. This approach can be seen in the work of the performance artist Michael René Sell. In the following, the role of norms and values in our society shall be considered. In particular, how the arts offer new approaches and food for thought vis-à-vis static rules. The term sociocultural personality stems from sociology. It describes the sum of thought, emotional and behavioural structures that people acquire in order to fulfil expectations from the social and cultural environment and to handle in it, too. That means that our behaviours are not born out of nature. Humans do not inherit them as children, but instead, adopt them from the environment, learn what they mean and learn when to act them out, through the process of socialization. This is one reason why we have such a cultural diversity in behavioural patterns and norms across the world. But what exactly are norms?

The term norm comes from Latin (norma) and means rule or right angle. Norms are behaviour based rules, which define to some extent what is appropriate and what is inappropriate in social interactions. Consequently, they determine how to react in certain situations. Since in one society similar set of rules are passed on, people expect a certain behaviour and reaction in their dealings with one another. The result is a simplified everyday life; norms tell us how to react in certain situations meaning that we do not have to reassess how to behave each time. We know how to behave because of learned schemas, e.g. how we greet each other. Also, this means that we are not surprised about what other people do and do not have to wonder about unexpected actions. Norms can be categorized in 'can', 'shall' and 'must' expectations. They differ in their priority to be followed as a requirement. Depending on the category, disregard of norms is considered differently. When for example one is entering a shop, and the vendor does not greet, it is seen as impolite, but this does not result in a formal report. Using physical violence, in this case, would be seen as contempt against common values. Thus, norms are adapted to different life situations. In contrast, values are the frame for

DOI: http://dx.doi.org/10.5617/jea.5440

fournal of Extreme Anthropology, Vol. 1, No. 2: 59-62, ISSN: 2535-3241 
norms. They are general ideas and conceptions from a community, which are seen as right and worth striving for. For instance, freedom of expression and charity can be considered as values. As mentioned earlier, norms are taught with the aim of internalizing them in the younger generation so that the individual absorbs them. Because norms are flexible and changeable, reflection on them is necessary to secure progress in society. Only through reflection, a change of values can take place. Of course, some values are permanent, for example not to murder another individual. The reason for that is the avoidance of a chaotic, anarchic co-existence and as well the need for self- preservation and security.

Old norms disappear when they are no longer seen as valuable or useful anymore for the present. Just looking to media discourses, one can see that norms and values are constantly questioned, and society is struggling with appropriate answers. A current example is the debate about the marriage for everybody or the role of the woman in the family unit or discussions about self-reliance and the freedom of the individual. At this point, we come back to the theory of post-materialism. Ronald Inglehart sees the reason for the rise of post-materialism in the social and economic conditions people grow up with. The older, post-war generation, aimed to build up prosperity as a reaction to the lack of the same. Security and stability were desired after an experience of a time without having them. In contrast, the younger generation already grew up with the wealth their parents created and were born into a stable system. Their basic needs are fulfilled, and they are looking for something else like the empowerment through individual rights, education and culture.

The art historian Carol Duncan sees in the change of values simultaneously a new creation of rituals regarding the new importance of culture and art. In particular, the museum- and gallery visits seem to have a similar structure and meaning as rituals. They have a fixed structure, which is repetitive and with a purpose. Advocates of this thesis say that visitors of museums and galleries 'come away with a sense of enlightenment or feeling of having been spiritually nourished' (Duncan 1995, 13), an experience otherwise just known within the religious context. Already back in the $18^{\text {th }}$ century, the relevance of visual art was analysed, as was the power of art to transform the viewers spiritually, morally and emotionally. Goethe for instance assumed with the appropriation of these new rituals that 'the negation or obscuring of other, older meanings' would take place (Duncan 1995, 16).

Philosophy and criticism have always played an important role in art. This indicates the outstanding character art has in forming public opinion and reflection on current discourses, and thus even the possibility of art changing and creating new values. But that does not mean that old values are disappearing. They co-exist and persist, albeit often in different forms - a plural and heterogeneous society is the result. The last performance of Michael René Sell showed that these values could be a reason for conflict. On Easter, the artist tied himself on a massive cross, which looked similar to a swastika. Moreover, art often gives impulses for rethinking old values and norms. His intention was to draw attention to the relationship between the church and the Nazi regime in the last century. Critiques and reflection combined in one art performance. But a lot of people saw that differently. Among them, a 70-year old man, who charged 
Sell and called the police stopping the performance after 10 minutes. For him and his fellows, it was a direct assault on his values and religion. Therefore, the expectation to act according to the values is seen as a 'must', and the reaction is harsh when one does not. The magazine Heute reported on the incident in April 2017. A user commented: 'an affront to Christianity.' The emotional response shows that differing ideas of values are presented by the artist, from those of the people going to church on Easter and for a majority of people in Austria, still feeling connected to religious values. On the one side, the striving for the values of free opinion, expression and criticism is represented by the artist - as opposed to traditionalism and religiosity. Post-materialism versus Materialism. One could even say we are witnessing here a confrontation of two forms of rituals that have emerged from two different states of value thinking. The example shows that performances and art in itself have the power to draw attention to these conflicts in society. Not only are they reflecting on old norms, values and their position in society, but also point to ways of creating new values. The question arises of how much empathy and understanding we have to show for different beliefs, and how we can peacefully combine them and accept one another. When is it right to hurt feelings in order to provoke a discussion? Who has to learn to be more tolerant? In the end, none of us is in possession of the total truth, and particularly when it comes to norms and values, it is not easy to judge. Yet, it is clear that tolerance of the beliefs of others can be the key to a lot of questions and current conflicts we are facing. Art has to be controversial in order to generate different opinions about life approaches towards certain topics. Moreover, to have an impact on us and make us reconsider common and accepted structures. Not only at the macro level, but even more importantly for ourselves as individuals. Because if nobody is questioning the given, how shall we progress and develop further as a society?

The exhibited object from Sell is made of a material, already used for various functions in his previous work. It invites the observer to become active and discover what the artist may want to share with people, showing curiosity and becoming, therefore, a subject, and crossing the border from being a silent observer.

2017. 'Das ist eine Frechheit gegen das Christentum!' Heute, April 15. http:// www.heute.at/community/leser/story/-Das-ist-eine-Frechheit-gegen-dasChristentum---55573460

Scheuer, Angelika. 2016. 'Materialistische und postmaterialistische Werte', Bundeszentrale für Politische Bildung, May 5. http://www.bpb.de/nachschlagen/datenreport-2016/226961/materialistischeund-postmaterialistische-werte

Bosančic, Saša, 2007. 'Werte, Normen und Rollen' (presentation for basic class sociology, University Augsburg) November 28.

Duncan, Carol. 1995. Civilizing Rituals. Inside Public Art Museum. London and New York: Routledge. 